\title{
FINITE ELEMENT MODEL FOR ULTRASONIC CLEANING
}

\author{
L. G. OLSON \\ Department of Mechanical Engineering, The University of Michigan, Ann Arbor, \\ Michigan 48109-2140, U.S.A.
}

(Received 21 October 1987, and in revised form 30 March 1988)

\begin{abstract}
Ultrasonic cleaning is modeled as a plane wave striking a sphere at the interface between a solid and a fluid (an axisymmetric fluid-structure interaction problem). To study this problem the $\phi-U-P_{0}$ finite element method has been used with direct time integration in a large bounded domain. Two well established analytical solutions approximate the conditions described in the current analysis and have been used to verify the time step size and finite element mesh. The force on the sphere due to the passage of the wave front has then been found for three wave frequencies. The maximum force occurs when the wavelength is comparable to the sphere diameter.
\end{abstract}

\section{INTRODUCTION}

Ultrasonic cleaning is extensively used in the semiconductor industry. One function served by the technique is to remove small particles. Most machines direct $100-1000 \mathrm{kHz}$ ultrasonic waves at the contaminated wafers through a solvent bath, but cannot regularly remove very small $(1 \mu \mathrm{m}$ diameter $)$ particles. In addition, it is not well understood how the acoustic waves in the solvent interact with the parts in the bath to produce this cleaning effect. Estimating the net forces produced on the contaminant particles by the acoustic waves presents a difficult analytical problem.

Therefore, in this study the ultrasonic cleaning process has been treated as a general fluid-structure interaction problem, and the governing equations have been solved numerically. The author is unaware of any previous work which applies numerical fluid-structure interaction techniques to ultrasonic cleaning.

The simplified axisymmetric fluid-structure interaction model to be considered involves a sphere at the interface between a solid and a fluid (see Figure 1$)$. A small $(\approx 1 \mu \mathrm{m}$ diameter) sphere rests on a semi-infinite elastic solid (silicon, which extends from $z=0$ to negative infinity). A stiff spring holds the sphere against the silicon. Water surrounds the sphere (extending to positive infinity). A plane wave of known frequency (in the range $10 \mathrm{MHz}$ to $1 \mathrm{GHz}$ ) travels through the silicon $\dagger$ and strikes the fluid-solid interface at normal incidence. Some of the wave's energy reflects back into the solid and some continues into the fluid. The quantity to be estimated is the force on the sphere (i.e., the force in the spring) due to the initial passage of the wave front. (Most of the cleaning effect should occur soon after the wave passes the particle.) Future analyses will involve more complicated geometries and include non-linear wave propagation effects.

Standard finite element techniques provide a useful baseline solution to this simple problem, since the finite element method can be extended to include complicated geometries and non-linear waves. Specifically the $\phi-U-P_{0}$ method $[1,2]$ can be used, in which the velocity potential $\phi$ is the nodal variable in the fluid and $P_{0}$ is the single

† Alternatively, the wave might just as easily come from the fluid side. 

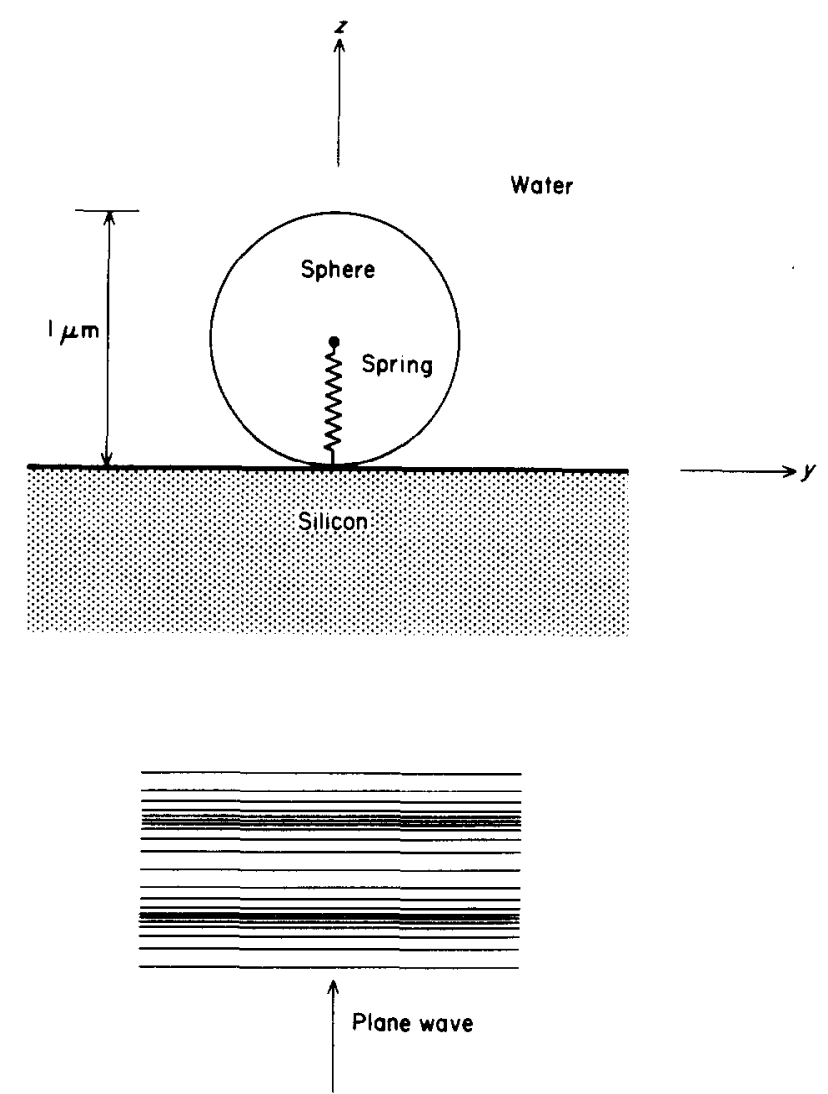

Figure 1. Sphere-spring-semi-infinite solid problem.

hydrostatic pressure in each fluid region. Since $P_{0}$ is zero in the case to be considered, this method reduces to Everstine's method [3-5]. These methods may be applied reliably to transient analyses and generate symmetric matrix equations.

Other fluid-structure interaction methods for finite element analysis have been developed but each has some drawbacks in this case. Displacement-based methods have been studied extensively by numerous researchers. Belytschko has used this approach extensively in linear and non-linear applications [6-9]. Bathe and Hahn [10] also developed a linear/non-linear formulation which was further studied by Olson and Bathe [11], Larsson and Svenkvist [12], and Sundqvist [13]. Additional research on displacement-based methods has been done by Wilson [14,15], Shugar and Katona [16], and Khalil and Hubbard [17]. However, as discussed by Hamdi, Ousset, and Verchery [18], Kiefling and Feng [19], Akkas, Akkay, and Yilmaz [20], and Olson and Bathe [11], the displacement-based methods often suffer from spurious rotations in dynamic analysis. Many authors have studied some form of potential-based method. Zienkiewicz and Newton [21] used pressure as the nodal variable in the fluid and displacements as the unknown in the solid, but this yields a set of unsymmetric matrix equations. Others, including Daniel [22], Petyt and Lim [23], Muller [24], and Craggs [25], employed similar formulations. Zienkiewicz and Bettess [26] and Belytschko [27] have surveyed work in the area of fluid-structure interactions.

In section 2 , the $\phi-U-P_{0}$ method is discussed. Section 3 deals with two limiting cases for this analysis-a plane wave travelling from the solid to the fluid and a plane wave scattered from a sphere in infinite fluid. The results for three frequencies for the full 
problem are presented in section 4. Finally, the results are summarized and future directions are discussed in section 5 .

\section{FORMULATION}

The $\phi-U-P_{0}$ finite element method incorporates several assumptions about the fluid and solid. The fluid is assumed to be inviscid, adiabatic, compressible, to undergo only small motions, and to have no body forces acting on it (the standard acoustic fluid assumptions). In addition the motion of the solid is also linear (small strains, etc.). (Figure 2 defines the general geometry.) The $\phi-U-P_{0}$ method has been discussed in an earlier paper [1] and the formulation is briefly reviewed here.

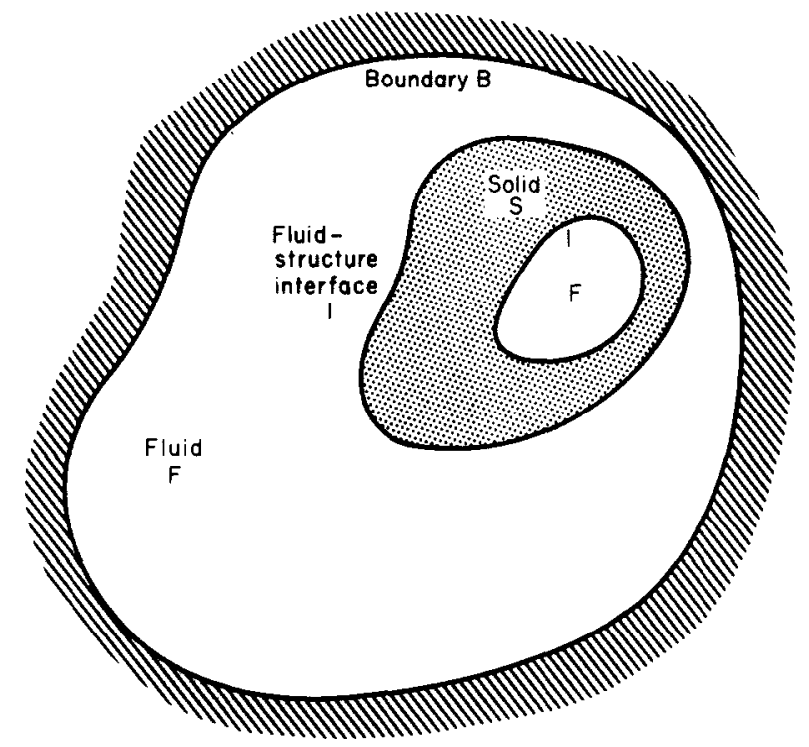

Figure 2. General fluid-structure interaction geometry.

\subsection{GOVERNING DIFFERENTIAL EQUATIONS FOR FLUID}

The governing differential equation for the inviscid, compressible, adiabatic fluid with no body forces is the wave equation [28]:

$$
(1 / \beta) \partial P_{0} / \partial t-(\rho / \beta) \partial^{2} \phi / \partial t^{2}+\nabla^{2} \phi=0,
$$

where $\beta$ is the isentropic bulk modulus of the fluid, $P_{0}$ is the hydrostatic pressure, $t$ is time, $\rho$ is the fluid density, and $\phi$ is the velocity potential $(V=\nabla \phi)$. In this equation the pressure is $P_{0}-\rho \dot{\phi}$, where $P_{0}$ has a single value within each fluid region. In this wave propagation analysis there is no change in $P_{0}$. Therefore one may set it to zero without loss of generality.

\subsection{VIRTUAL WORK EXPRESSIONS}

The symmetric virtual work expression for the fluid is [1]

$$
-\int \frac{\rho^{2}}{\beta} \frac{\partial^{2} \phi}{\partial t^{2}} \delta \phi \mathrm{d} F-\int \rho \nabla \phi \cdot \nabla \delta \phi \mathrm{d} F-\int \rho \frac{\partial U_{n}}{\partial t} \delta \phi \mathrm{d} I=0,
$$

where $\delta x$ is the variation in $x, \mathrm{~d} F$ is the differential fluid volume, $U_{n}$ is the normal displacement of the solid, and $\mathrm{d} I$ is the differential fluid-structure interface. 
Virtual work expressions and variational indicators for continuum solids are well known [30]. For this application the virtual work expression has been used in the form [1]

$$
\int \delta \varepsilon^{\mathrm{T}} \mathbf{C}_{S} \varepsilon \mathrm{d} S+\int \rho_{s} \delta \mathbf{U}^{\mathrm{T}} \ddot{\mathbf{U}} \mathrm{d} S=\int \delta \mathbf{U}^{\mathrm{T}} \mathbf{f}^{A} \mathrm{~d} I+\int \delta U_{n} \rho \frac{\partial \phi}{\partial t} \mathrm{~d} I,
$$

where $\boldsymbol{\varepsilon}$ is the strain tensor in compacted form, $\mathbf{C}_{S}$ is the stress-strain matrix, $\mathrm{d} S$ is the differential solid volume, $\rho_{s}$ is the density of the solid, and $f_{A}$ is the vector of the externally applied loads.

\subsection{FINITE ELEMENT DISCRETIZATION}

The entire domain can now be discretized into finite elements (see Figure 3). The fluid is divided into isoparametric fluid elements and the solid into standard isoparametric

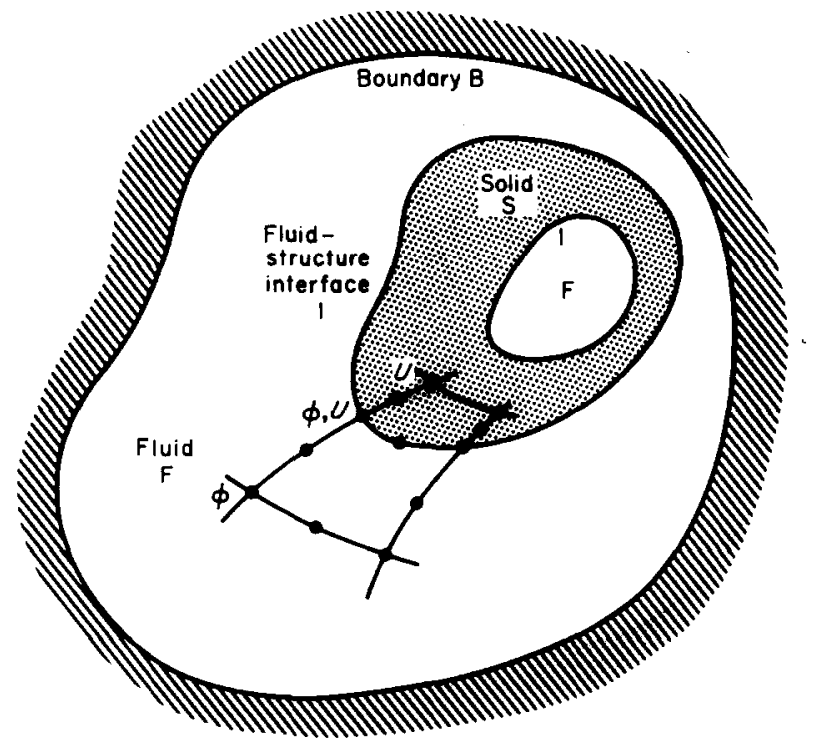

Figure 3. Discretization of general fluid-structure interaction geometry.

continuum solid elements. At the boundary between the fluid and the solid fluid-structure interface elements are used. Fluid elements have velocity potentials as the nodal variables. As a result each fluid element contributes two matrices:

$$
\mathbf{K}_{F F}^{\rho}=\int \rho \mathbf{G}^{\mathrm{T}} \mathbf{G} y \mathrm{~d} y \mathrm{~d} z \quad \text { and } \quad \mathbf{M}_{F F}^{e}=\int \frac{\rho^{2}}{\beta} \mathbf{h}^{\mathrm{T}} \mathbf{h} y \mathrm{~d} y \mathrm{~d} z .
$$

(Here

$$
\mathbf{G}=\left[\begin{array}{llll}
\frac{\partial h_{1}}{\partial y} & \frac{\partial h_{2}}{\partial y} & \ldots & \frac{\partial h_{N}}{\partial y} \\
\frac{\partial h_{1}}{\partial z} & \frac{\partial h_{2}}{\partial z} & \ldots & \frac{\partial h_{N}}{\partial z}
\end{array}\right], \quad \mathbf{h}=\left[\begin{array}{llll}
h_{1} & h_{2} & \cdots & h_{N}
\end{array}\right]
$$

and $h_{i}$ is the shape function for node $i$. The system is axisymmetric about the $z$ axis.) Continuum solid elements have displacements as the nodal variables and therefore contribute ordinary stiffness and mass matrices, $\mathbf{K}_{s s}^{e}$ and $\mathbf{M}_{s s}^{e}$. The fluid-structure interface elements enforce the coupling between the fluid and the solid. (If the fluid-structure interface elements are omitted the solid will behave as if there is no fluid and the fluid 
will act as though the solid is rigid.) The interface elements have displacements and velocity potentials as variables. They introduce an additional matrix,

$$
\mathbf{C}_{F S}^{e}=-\int \rho \mathbf{a}^{\mathrm{T}} \mathbf{b} y \mathrm{~d} i
$$

where

$$
\mathbf{a}=\left[\begin{array}{llll}
h_{1} & h_{2} & \cdots & h_{M}
\end{array}\right], \quad \mathbf{b}=\left[\begin{array}{lllllll}
h_{1} n_{y} & h_{1} n_{z} & h_{2} n_{y} & h_{2} n_{z} & \cdots & h_{M} n_{y} & h_{M} n_{z}
\end{array}\right],
$$

$M$ is the number of nodes in these surface elements, and di represents the length of the surface element.

The overall matrix equations for wave propagation, after the contributions from each element have been summed, may be represented by

$$
\left[\begin{array}{cc}
\mathbf{K}_{S S} & \mathbf{0} \\
\mathbf{0} & -\mathbf{K}_{F F}
\end{array}\right]\left[\begin{array}{c}
\mathbf{U} \\
\boldsymbol{\Phi}
\end{array}\right]+\left[\begin{array}{cc}
\mathbf{0} & \mathbf{C}_{F S}^{\mathrm{T}} \\
\mathbf{C}_{F S} & \mathbf{0}
\end{array}\right]\left[\begin{array}{c}
\dot{\mathbf{U}} \\
\dot{\boldsymbol{\Phi}}
\end{array}\right]+\left[\begin{array}{cc}
\mathbf{M}_{S S} & \mathbf{0} \\
\mathbf{0} & -\mathbf{M}_{F F}
\end{array}\right]\left[\begin{array}{c}
\ddot{\mathbf{U}} \\
\ddot{\boldsymbol{\Phi}}
\end{array}\right]=\left[\begin{array}{c}
\mathbf{R}_{S} \\
\mathbf{0}
\end{array}\right]
$$

or

$$
\mathbf{K X}+\mathbf{C} \dot{\mathbf{X}}+\mathbf{M} \ddot{\mathbf{X}}=\mathbf{R} .
$$

Four important features of this form should be noted. (1) The $\mathbf{K}, \mathbf{C}$, and $\mathbf{M}$ matrices are symmetric. (2) Although a $\mathbf{C}$ matrix has been introduced which multiplies the $\dot{\mathbf{X}}$ vector, it simply contains coupling terms and does not represent damping (since there is no physical damping in the finite system). (3) With proper equation ordering the bandwidth of the system can be quite narrow. (4) The matrix equations may be integrated directly in time by using Newmark's method.

\subsection{UNITS}

In a fluid-structure interaction analysis by the $\phi-U-P_{0}$ method the governing matrix equations may be numerically ill-conditioned for some choices of units. For this problem the units chosen were as follows: length, $1 \mu \mathrm{m}$; time, $1 \mathrm{~ns}$; mass, $1 \mathrm{pg}$. As a result the physical parameters of the system are the following: $\rho=1 \mathrm{pg} / \mu \mathrm{m}^{3} ; \beta=2 \cdot 1 \mathrm{pg} / \mathrm{ns}^{2} \mu \mathrm{m}$; $\rho_{s}=2 \cdot 3 \mathrm{pg} / \mu \mathrm{m}^{3} ; E=190 \mathrm{pg} / \mathrm{ns}^{2} \mu \mathrm{m}$; sphere diameter $=1 \mu \mathrm{m}$. If $R$ is a characteristic radius $(10 \mu \mathrm{m})$ and $L$ is a characteristic element length $(1 \mu \mathrm{m})$ then the orders of magnitude of the various element matrices become $K_{F F} \approx \rho R \approx 10 \mathrm{pg} / \mu \mathrm{m}^{2}, K_{S s} \approx E R \approx 1900 \mathrm{pg} / \mathrm{ns}^{2}$, $C_{F S} \approx \rho R L \approx 10 \mathrm{pg} / \mu \mathrm{m}, \quad M_{F F} \approx \rho^{2} R L^{2} / \beta \approx 5 \mathrm{pg} \mathrm{ns} / \mu \mathrm{m}^{2}$, and $M_{S S} \approx \rho_{s} R L^{2} \approx 20 \mathrm{pg}$. Although the physical meanings of the various terms are different they vary only from 5 to 2000 in magnitude.

\section{LIMITING CASES}

One may choose the time step and element sizes based on a knowledge of the forcing function frequency and wave propagation speeds in the fluid and solid. To verify these choices two limiting cases were analyzed. In the first case a plane wave passes from the solid into the fluid. In the second case a plane wave moves through the fluid to strike a rigid sphere.

\subsection{Plane WAVE PROPAGATION TEST}

Figure 4 shows the geometry under consideration. A semi-infinite half plane of silicon is adjacent to a semi-infinite half-plane of water. A $1 \mathrm{GHz}$ sinusoidal plane wave passes through the silicon striking the interface at normal incidence. Some of the wave is reflected back into the solid and the rest of the wave passes into the fluid. 

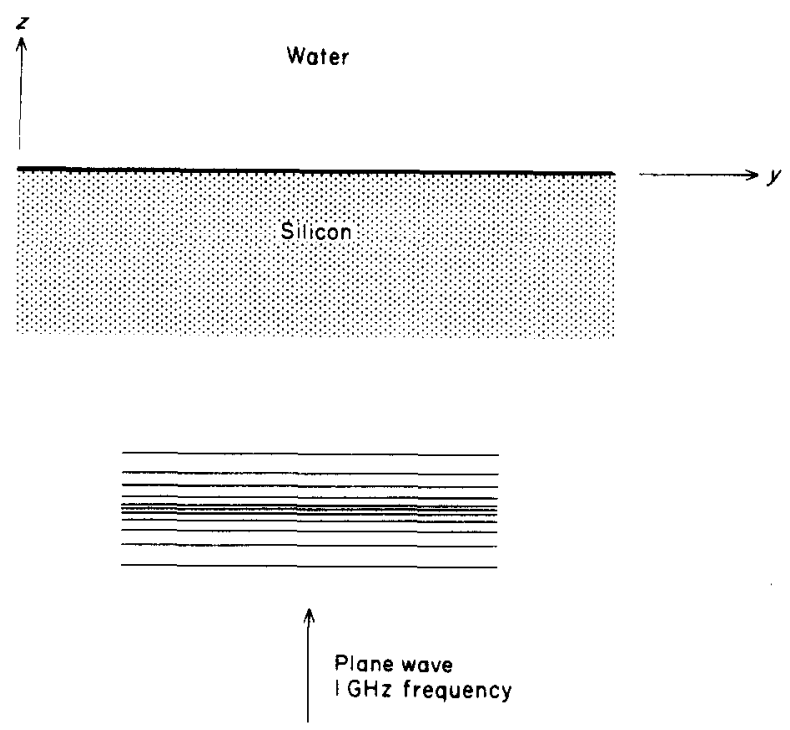

Figure 4. Plane wave propagation test.

The analytical solution to this problem is well known [28]. The wave originates in the solid so that the total displacement in the solid consists of the incident wave $\left(u_{i}\right)$ and the reflected wave $\left(u_{r}\right)$

$$
u=u_{i}\left(\frac{z}{c_{s}}-t\right)+u_{r}\left(\frac{z}{c_{s}}+t\right),
$$

where $c_{s}\left(=\sqrt{E / \rho_{s}}\right)$ is the speed of sound in the solid. The fluid contains only the transmitted wave $\left(\phi_{t}\right)$

$$
\phi=\phi_{t}\left(\frac{z}{c_{f}}-t\right),
$$

with $c_{f}\left(=\sqrt{\beta / \rho_{f}}\right)$ the speed of sound in the fluid. Two conditions must be satisfied by these waves. First, the pressure in the fluid must match the pressure in the solid at the interface:

$$
\rho \partial \phi / \partial t=E \partial u /\left.\partial z\right|_{z=0} .
$$

Second, the velocity in the fluid must match the velocity in the solid at the interface:

$$
\partial u / \partial t=\partial \phi /\left.\partial z\right|_{z=0} \text {. }
$$

Applying these two conditions gives

$$
\phi_{t} / u_{i}=c_{f}(-2 \alpha) /(1+\alpha),
$$

where $\alpha=\sqrt{E \rho_{s} / \beta \rho}$. For the problem under consideration $\alpha=14.43$ so that $\phi_{i} / u_{i}=$ $-2.71 \mu \mathrm{m} / \mathrm{ns}$ is the ratio of the magnitude of the transmitted velocity potential wave to the incident displacement wave.

Figure 5 shows the finite element mesh used to analyze this test case. The wavelength of the wave in the solid is $9.09 \mu \mathrm{m}$ so that $18 \mu \mathrm{m}$ of solid is modeled with elements $2.0 \mu \mathrm{m}$ long. In the fluid the wavelength becomes $1.45 \mu \mathrm{m}$ and 9 elements are used in $3.0 \mu \mathrm{m}$ of water. (Notice that 54 elements are used in $18 \mu \mathrm{m}$ for the width of both the fluid and the solid.) The period of the $1 \mathrm{GHz}$ wave is $1 \mathrm{~ns}$ so a time step of $0.05 \mathrm{~ns}$ with Newmark's 




Figure 5. Finite element mesh for plane wave propagation test.

method (trapezoidal rule) was chosen for time integration. A sinusoidal prescribed displacement (with $1 \mu \mathrm{m}$ amplitude and $1 \mathrm{GHz}$ frequency) was used to generate the wave in the solid.

As shown in Figure 6, after 30 time steps $(1.5 \mathrm{~ns})$ the displacement wave has the correct amplitude and period. After 60 time steps $(3.0 \mathrm{~ns}$, see Figure 7$)$ the wave has partially reflected off of the interface. The amplitude of the imposed displacement wave was $1.0 \mu \mathrm{m}$ so that one expects the transmitted velocity potential wave to have an amplitude of $2 \cdot 71$. The finite element solution shows a value between 2.49 and $2.77 \mu \mathrm{m}^{2} / \mathrm{ns}$. (Notice that the solid wave is the superposition of the incident and reflected waves so that one cannot calculate its profile easily.) After 70 time steps (3.5 ns, see Figure 8) the solution has

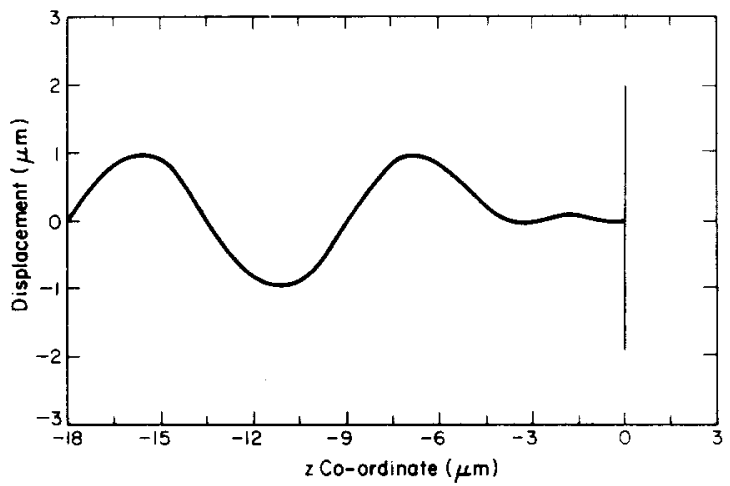

Figure 6. Results for plane wave propagation test (after 1.5 ns). Displacement: $\max 1.00 ; \min -0.97$. 


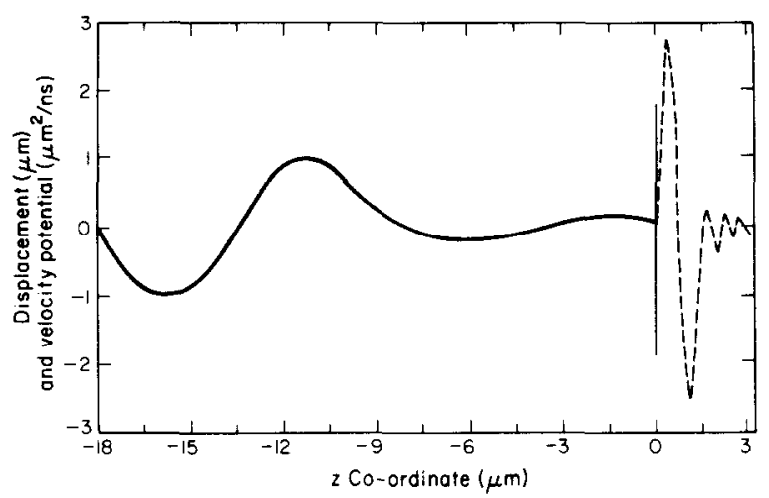

Figure 7. Results for plane wave propagation test (after $3.0 \mathrm{~ns}$ ). Velocity potential in fluid (- - ). $\max 2 \cdot 77$; $\min -2.49$; displacement of solid (-) $\max 1.02, \min -0.98$.

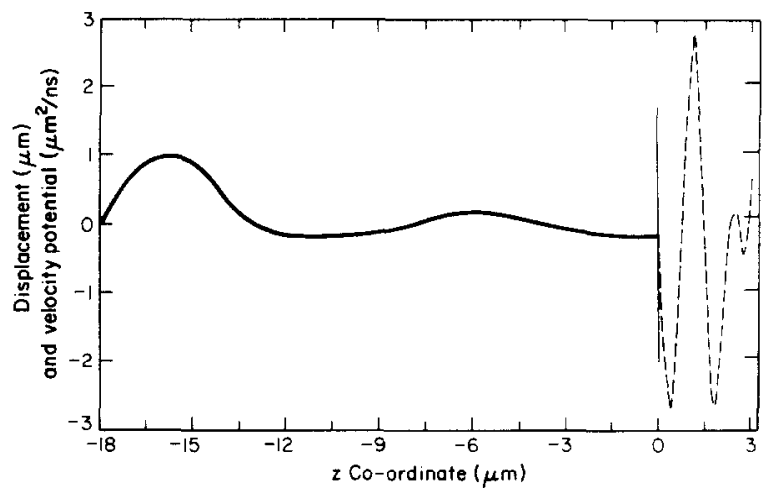

Figure 8. Results for plane wave propagation test (after $3.5 \mathrm{~ns}$ ). Velocity potential in fluid (- - ) : $\max 2 \cdot 71$, $\min -2 \cdot 67$; displacement of solid $(-)$ : $\max 0 \cdot 96, \min -0 \cdot 16$.

nearly reached the edge of the finite element domain. However, it indicates an amplitude of 2.67 to $2 \cdot 71 \mu \mathrm{m}^{2} / \mathrm{ns}$.

\subsection{PLANE WAVE SCATTERING TESTS}

Figure 9 shows the geometry under consideration. A plane wave moves through the fluid and strikes a rigid sphere. The force on the sphere is to be calculated.

The analytical solution to this problem is also well established [28]. The pressure $p_{t}$ on any point of a sphere (radius $a$ ) struck by a plane pressure wave $\left(p \mathrm{e}^{-\mathrm{i} \omega t}\right)$ is given approximately by

$$
p_{t} \approx\left(1+\frac{3 \mathrm{i} \omega a \cos \theta}{2 c_{f}}\right) p \mathrm{e}^{-\mathrm{i} \omega t},
$$

where $\theta$ is the angle from the polar axis. This relationship is valid when the size of the sphere is much smaller than the wavelength of the plane wave (i.e., for $\omega a / c \ll 1$ ). The total force on an axisymmetric 1 radian slice of this sphere is

$$
F \approx a^{2} \int_{0}^{\pi} p_{t} \cos \theta \sin \theta \mathrm{d} \theta, \quad \text { or } \quad F \approx\left(i \omega a^{3} / c_{f}\right) p \mathrm{e}^{-\mathrm{i} \omega t} .
$$

Here there is a prescribed velocity potential so

$$
p=-\mathrm{i} \omega \rho \phi
$$




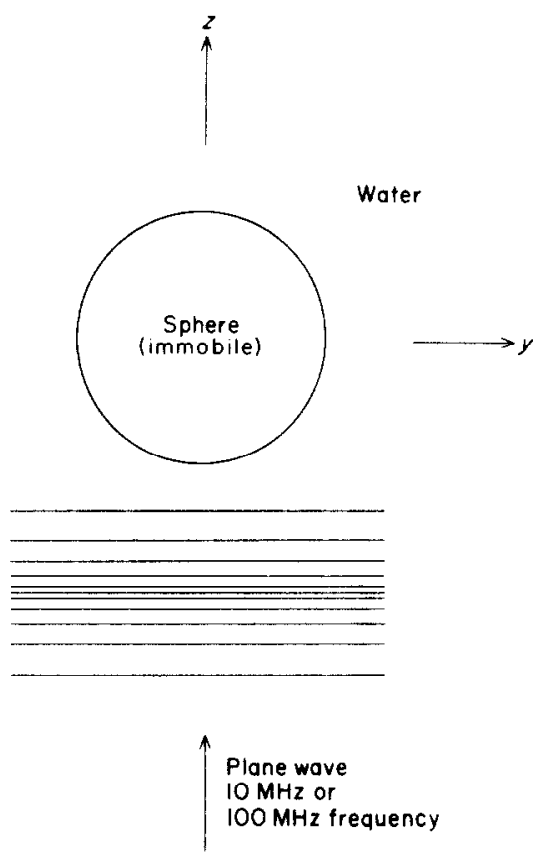

Figure 9. Plane wave scattering test.

gives

$$
F \approx\left(\omega^{2} a^{3} / c_{f}\right) \rho \phi \mathrm{e}^{-\mathrm{i} \omega t} .
$$

Note that the force is in phase with the velocity potential and that the force is proportional to the square of the frequency.

If the magnitude of the velocity potential wave $\phi$ is $1.0 \mu \mathrm{m}^{2} / \mathrm{ns}$ then the force on the sphere will be $F \approx 0.000340 \mathrm{pg} /(\mu \mathrm{m} \mathrm{ns})=0.0340$ dynes for a $10 \mathrm{MHz}$ wave, and $F \approx$ $0.0340 \mathrm{pg} /(\mu \mathrm{m} \mathrm{ns})=3.40$ dynes for a $100 \mathrm{MHz}$ wave.

In addition to the physical parameters of the problem one must choose a spring to prevent the sphere from moving while allowing the net force on the sphere to be measured. The spring must be sufficiently stiff to prevent most of the sphere motion but the resonance between the spring stiffness and the added mass of the sphere should be far from the frequencies of interest. (The sphere itself is modelled as massless.) A stiffness of $10^{5} \mathrm{pg} / \mathrm{ns}^{2}$ was used, which gives a resonance at approximately $100 \mathrm{GHz}$ and also gives displacements of $\approx 10^{-9} \mu \mathrm{m}$ for a $10 \mathrm{MHz}$ wave.

\subsection{1. $10 \mathrm{MHz}$ Test}

Figure 10 shows the mesh for the $10 \mathrm{MHz}$ plane wave scattering test. Near the sphere the mesh of elements is quite fine while far from the sphere the element sides increase to $40 \mu \mathrm{m}$ (the wavelength in the fluid is $145 \mu \mathrm{m}$ at $10 \mathrm{MHz}$ ). Figure 11 shows the region near the rigid massless sphere. Figure 12 shows the prescribed velocity potential used to generate the plane wave. (Notice that the wave is smooth near $t=0$ to reduce spurious high frequency noise in the numerical solution.) Figure 13 shows the resulting force on the sphere versus time. At first there is no force on the sphere since the wave has not yet reached the sphere. Next some high frequency wave components strike the sphere (see section 3.2.3). Finally the true wave strikes the sphere. It causes a large force on the sphere which we measure for approximately 1.5 cycles. One cannot accurately follow the wave after this time since the wavefront has already reached the boundary of the finite 


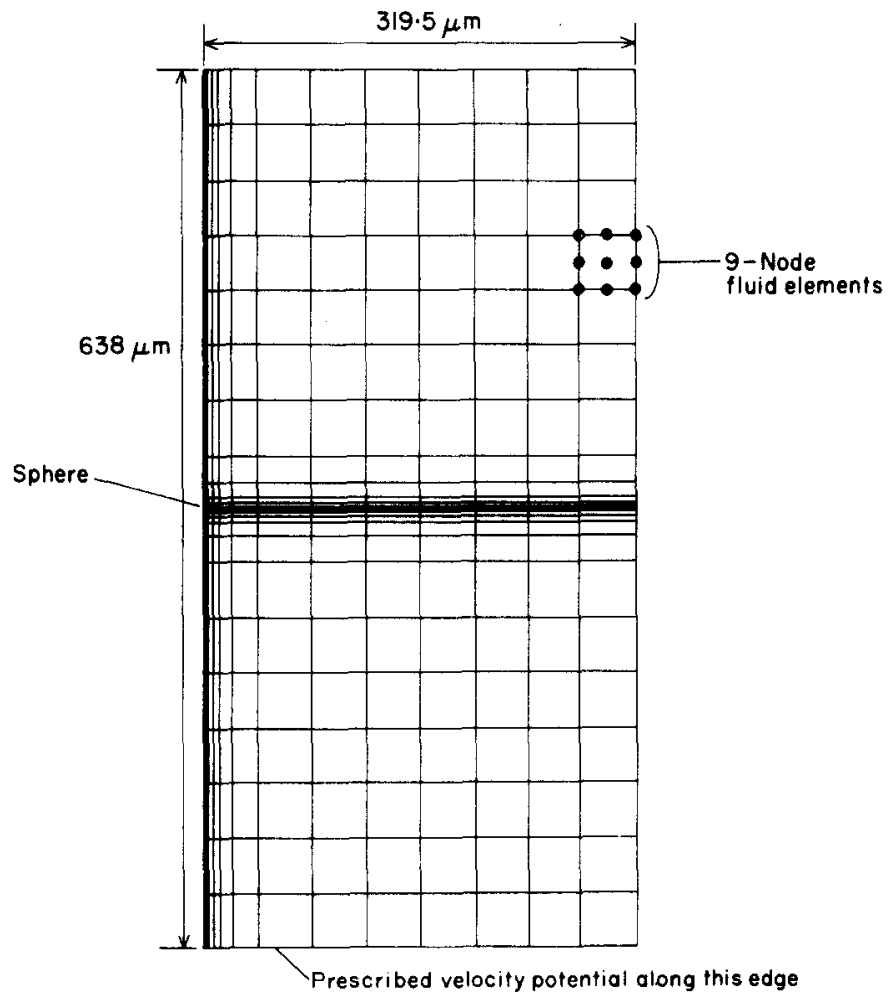

Figure 10. Finite element mesh for $10 \mathrm{MHz}$ plane wave scattering test.

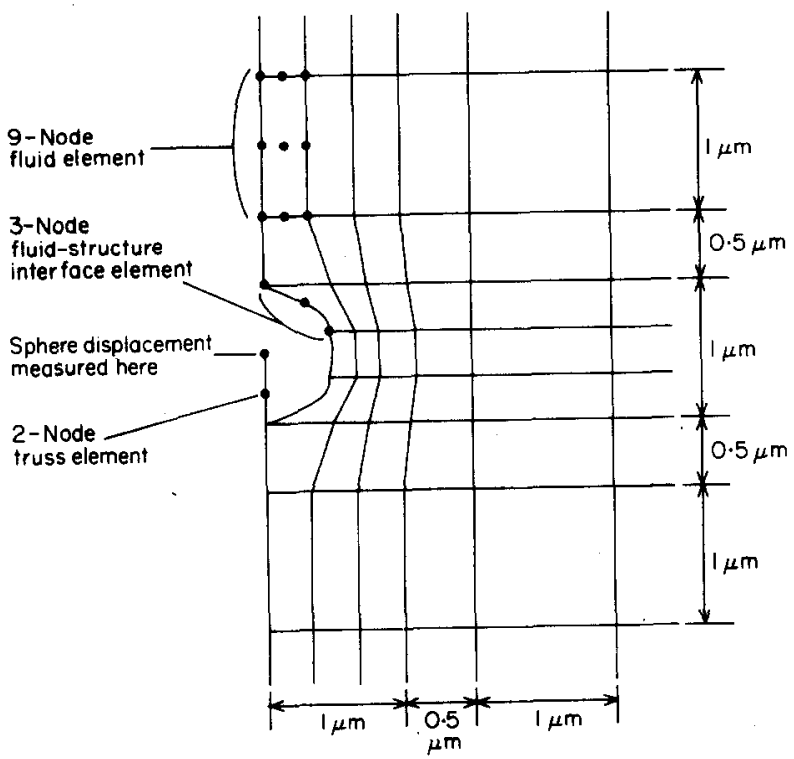

Figure 11. Mesh near sphere for $10 \mathrm{MHz}$ plane wave scattering test. 


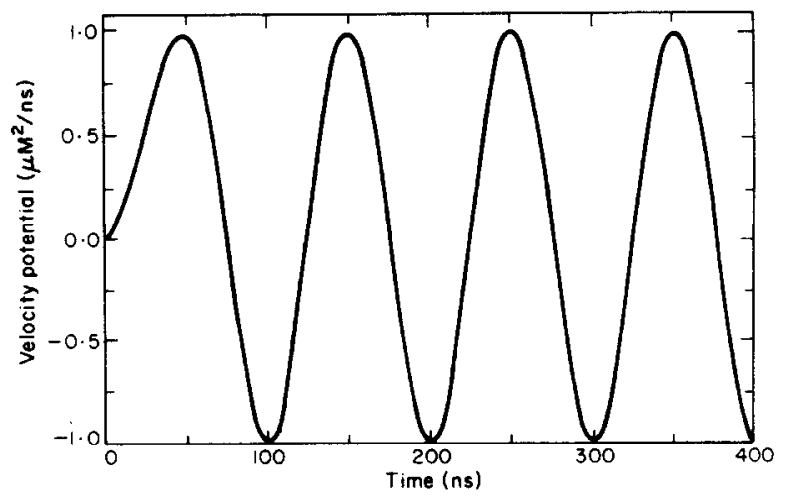

Figure 12. Prescribed velocity potential for $10 \mathrm{MHz}$ plane wave scattering test.

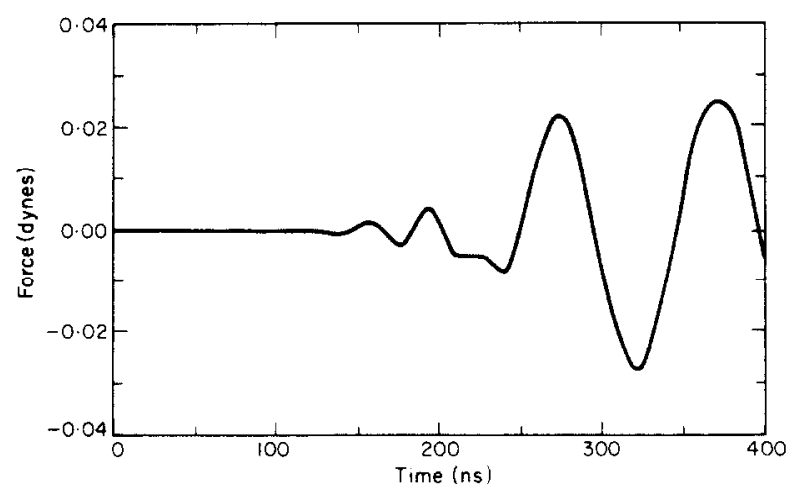

Figure 13. Force on sphere for $10 \mathrm{MHz}$ plane wave scattering test.

element mesh. Note that the behavior of the wave is qualitatively correct although the amplitude is roughly $20 \%$ too small.

\subsection{2. $100 \mathrm{MHz}$ Test}

To verify the frequency dependence of the force on the sphere a $100 \mathrm{MHz}$ plane wave scattering test was performed. Figure 14 shows the mesh used. The region around the sphere is the same as in Figure 11. The prescribed velocity potential is identical to the function used in the $10 \mathrm{MHz}$ test except for the time scaling factor of 10 .

As shown in Figure 15 the force on the sphere as a function of time is very similar to that in the plot for $10 \mathrm{MHz}$ except for the factor of 100 due to the change in frequency. Once again the results are qualitatively correct but are too small in magnitude by roughly $20 \%$.

\subsubsection{Sources of error}

These plane wave scattering results show larger errors than the plane wave propagation test and two major factors probably account for the $20 \%$ discrepancy in force between the analytical and numerical results. First, the numerical time stepping algorithm introduces errors. Second, the sphere was not modelled very accurately with only three parabolic elements.

Numerical time stepping always introduces some solution errors. Using Newmark's method (trapezoidal rule) one ordinarily expects to find period elongation but no 


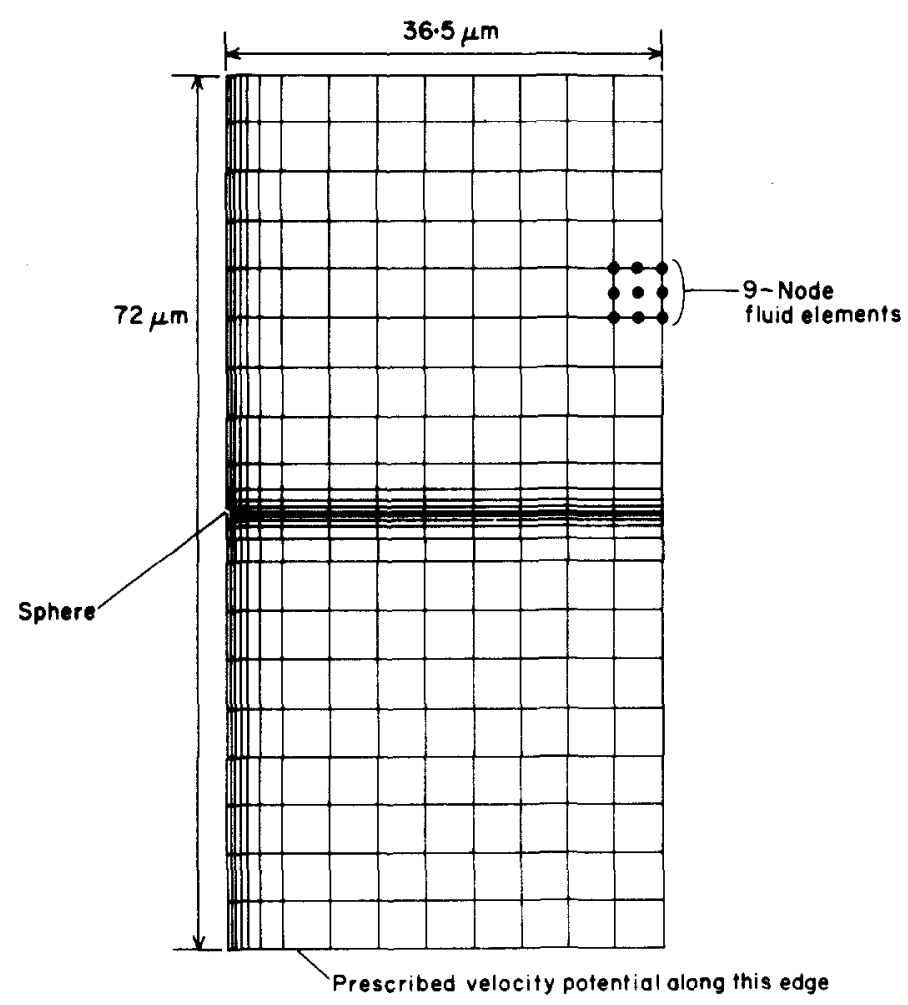

Figure 14. Finite element mesh for $100 \mathrm{MHz}$ plane wave scattering test.

amplitude decay [30]. The prescribed velocity potential used has only one frequency component in the steady state but near $t=0$ additional high frequency components are introduced in starting the system. These high frequency components have large period elongation errors and therefore move "faster" than the more accurately reproduced fundamental frequency (this has been observed by other researchers [31]). As seen in Figures 13 and 15 they introduce initial errors of $10-20 \%$ in the solution. One expects these effects to decrease or remain constant with time so that some of the long time error can be attributed to these high frequency components.

Modelling the sphere with only three parabolic elements introduces other errors. In a previous study [1] significant variations were found in the added mass calculated for an

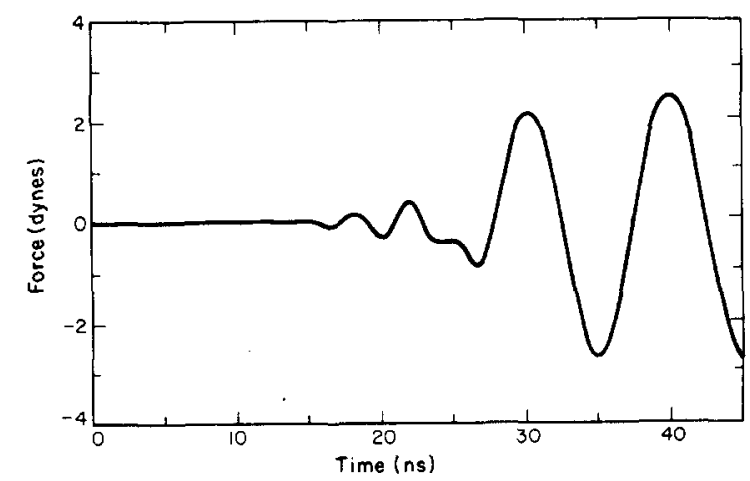

Figure 15. Force on sphere for $100 \mathrm{MHz}$ plane wave scattering test. 
ellipse due to small changes in the geometry (see Figure 16). A low frequency plane wave passing over a sphere induces an added mass-like effect and thus similar errors should be expected. It was decided not to refine the model of the sphere since interest here is in general trends rather than specific force values.
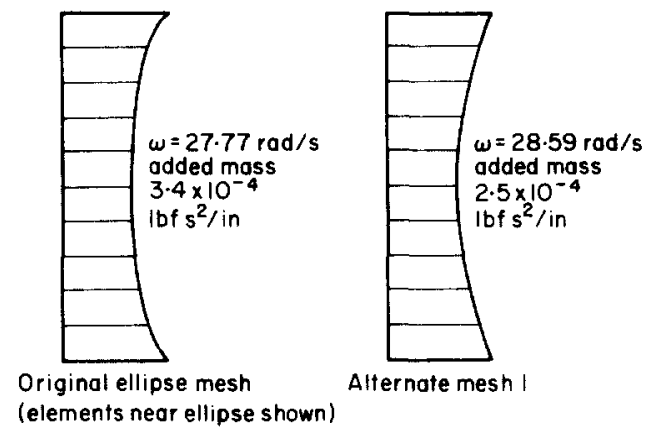

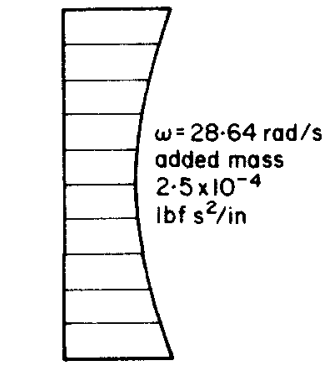

Alternate mesh 2

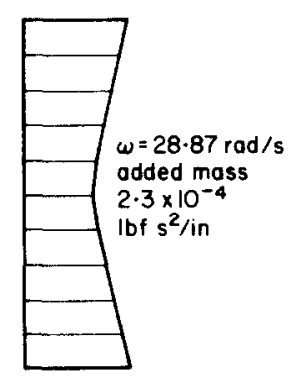

Alternate mesh 3

Figure 16. Added mass calculated for several ellipse-like shapes.

\section{FORCE ON SPHERE AT FLUID-STRUCTURE INTERFACE}

Having identified appropriate element mesh and time step sizes and examined the accuracy of the method on some problems with known solutions one can return to the original problem: i.e. to find the force on a sphere resting on a fluid-solid interface for waves at $10 \mathrm{MHz}, 100 \mathrm{MHz}$, and $1 \mathrm{GHz}$.

\subsection{MESHES AND RESULTS FOR THREE FREQUENCIES}

For the $10 \mathrm{MHz}$ case Figures 17 and 18 detail the finite element mesh. The $1 \mu \mathrm{m}$ amplitude prescribed displacement function has the form shown in Figure 12. Nine-node elements were used in the fluid and the solid and the sphere was modeled as a massless object attached to the solid with a stiff spring $\left(10^{5} \mathrm{pg} / \mathrm{ns}^{2}\right)$. Figure 19 shows the results for the sphere force versus time.

The magnitude of the force was calculated as approximately 0.015 dynes. The force as a function of time appears to be quite reasonable although the amplitude is not as large as might be expected from the plane wave scattering tests.

At $100 \mathrm{MHz}$ the mesh shown in Figure 20 was used. The mesh near the sphere is the same as for the $10 \mathrm{MHz}$ case (Figure 18). Figure 21 shows the result for the force on the sphere which indicates a value of $\approx 1.5$ dynes. Since the frequency is increased by a factor of 10 one expects (based on the wave scattering results) that the force on the sphere will simply increase by a factor of 100 . Comparing Figures 19 and 21 shows that this is indeed the case. 


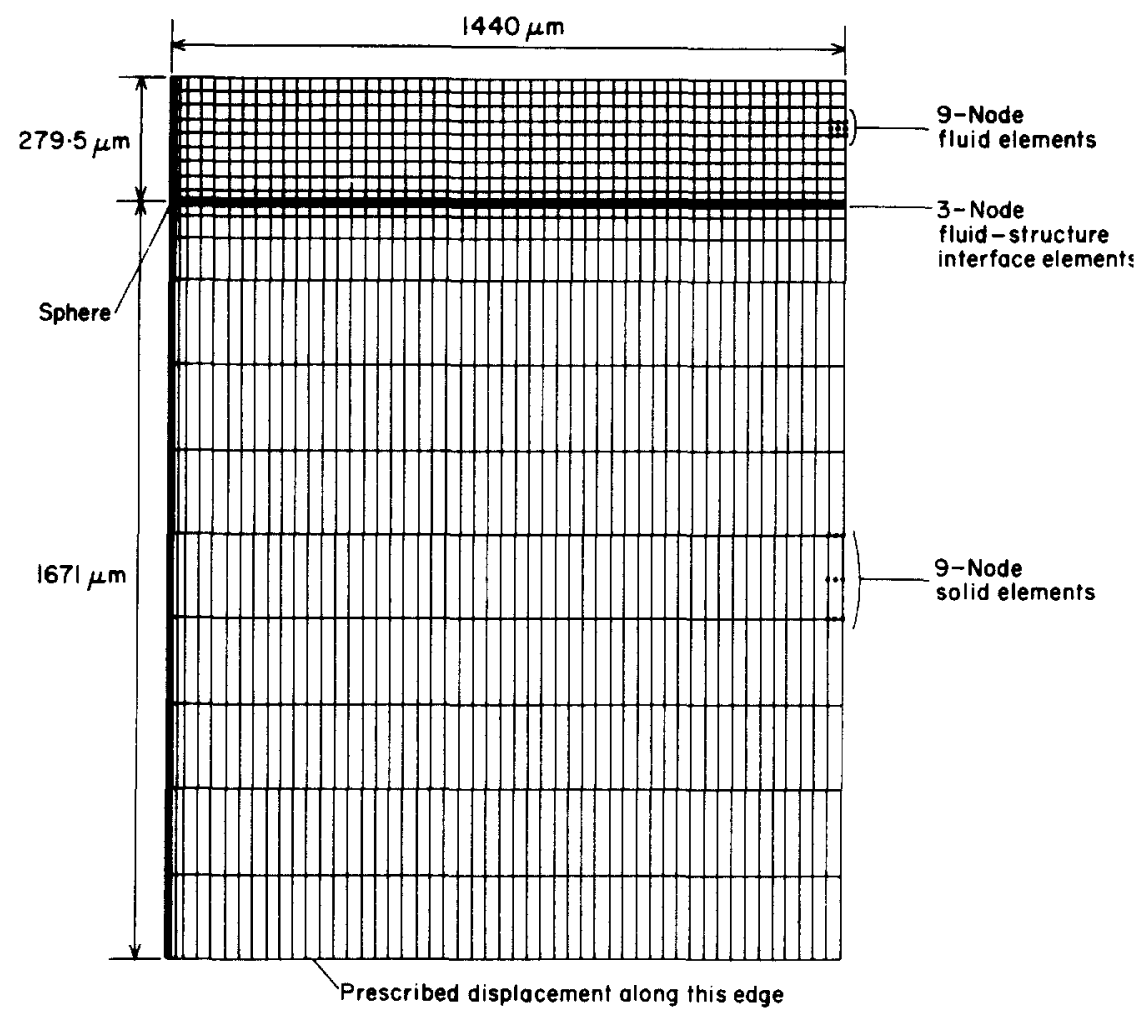

Figure 17. Finite element mesh for $10 \mathrm{MHz}$ case.

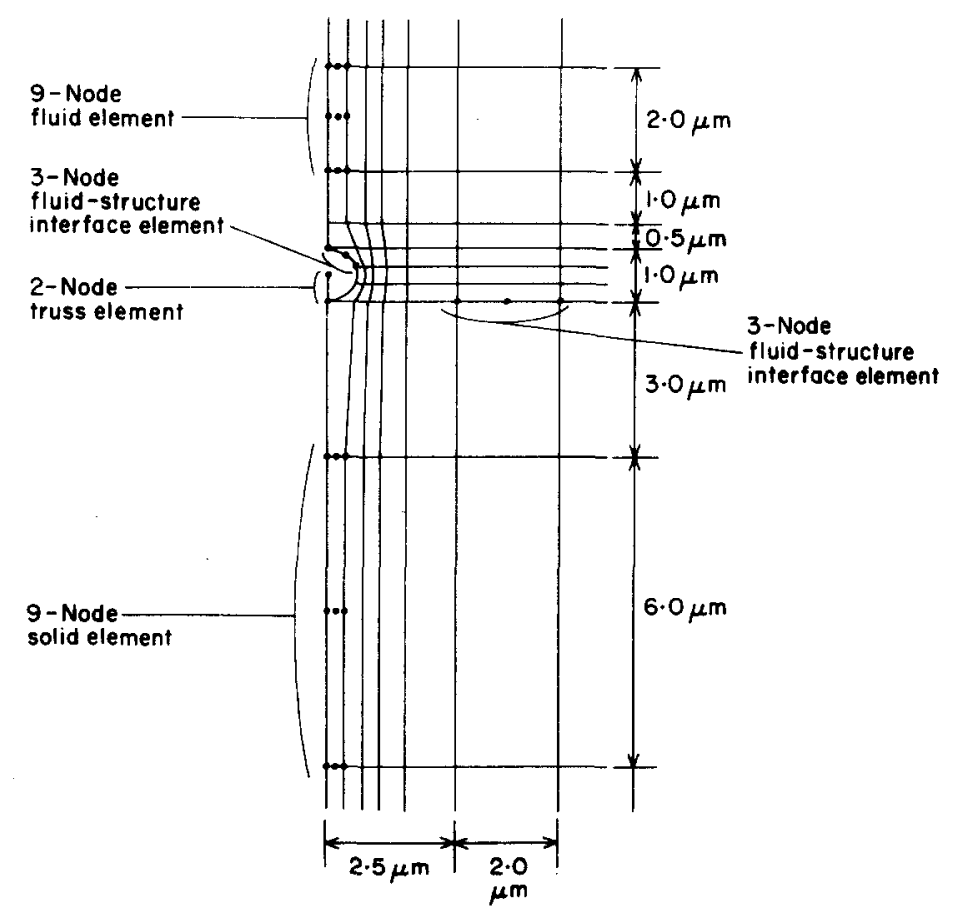

Figure 18. Finite element mesh near sphere for $10 \mathrm{MHz}$ and $100 \mathrm{MHz}$ cases. 


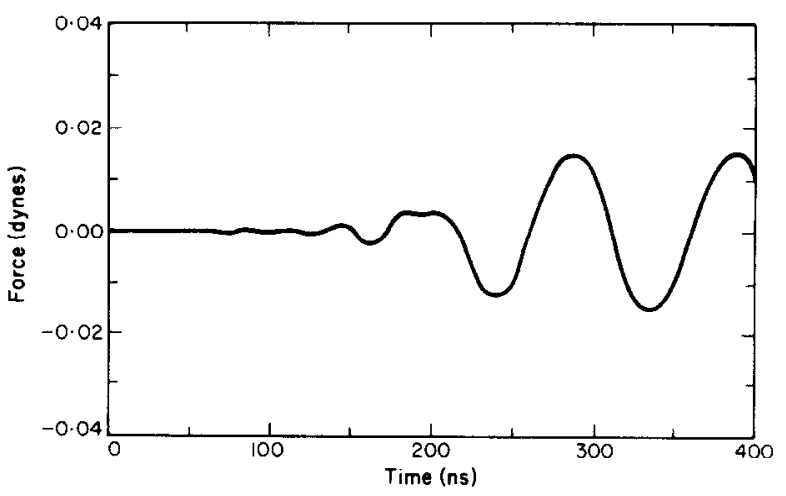

Figure 19. Force on sphere for $10 \mathrm{MHz}$ case.

Figures 22 and 23 detail the mesh for the $1 \mathrm{GHz}$ analysis. As shown in Figure 24 the magnitude of the force on the sphere is roughly 130 dynes. Notice that, although the frequency is increased by a factor of 10 , the force is increased by less than a factor of 100. This is reasonable since for the $1 \mathrm{GHz}$ case $\omega a / c_{f}=2 \cdot 2$, so that equation (18) is no longer valid and one does not expect the force to be directly proportional to the square of the frequency.

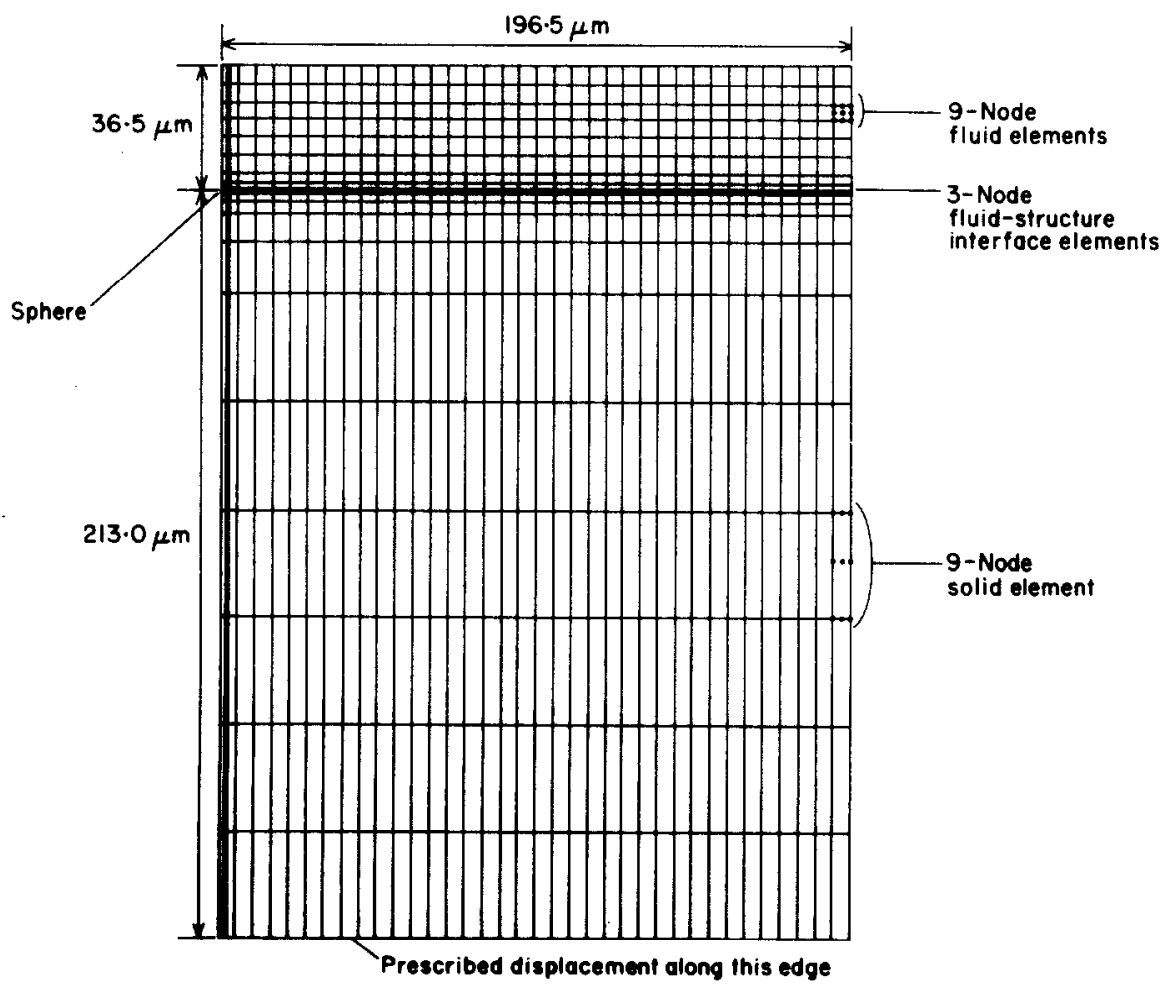

Figure 20. Finite element mesh for $100 \mathrm{MHz}$ case. 


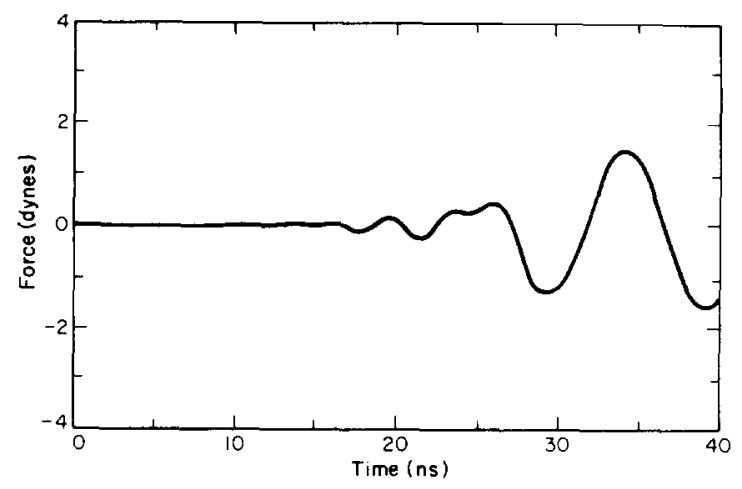

Figure 21. Force on sphere for $100 \mathrm{MHz}$ case.

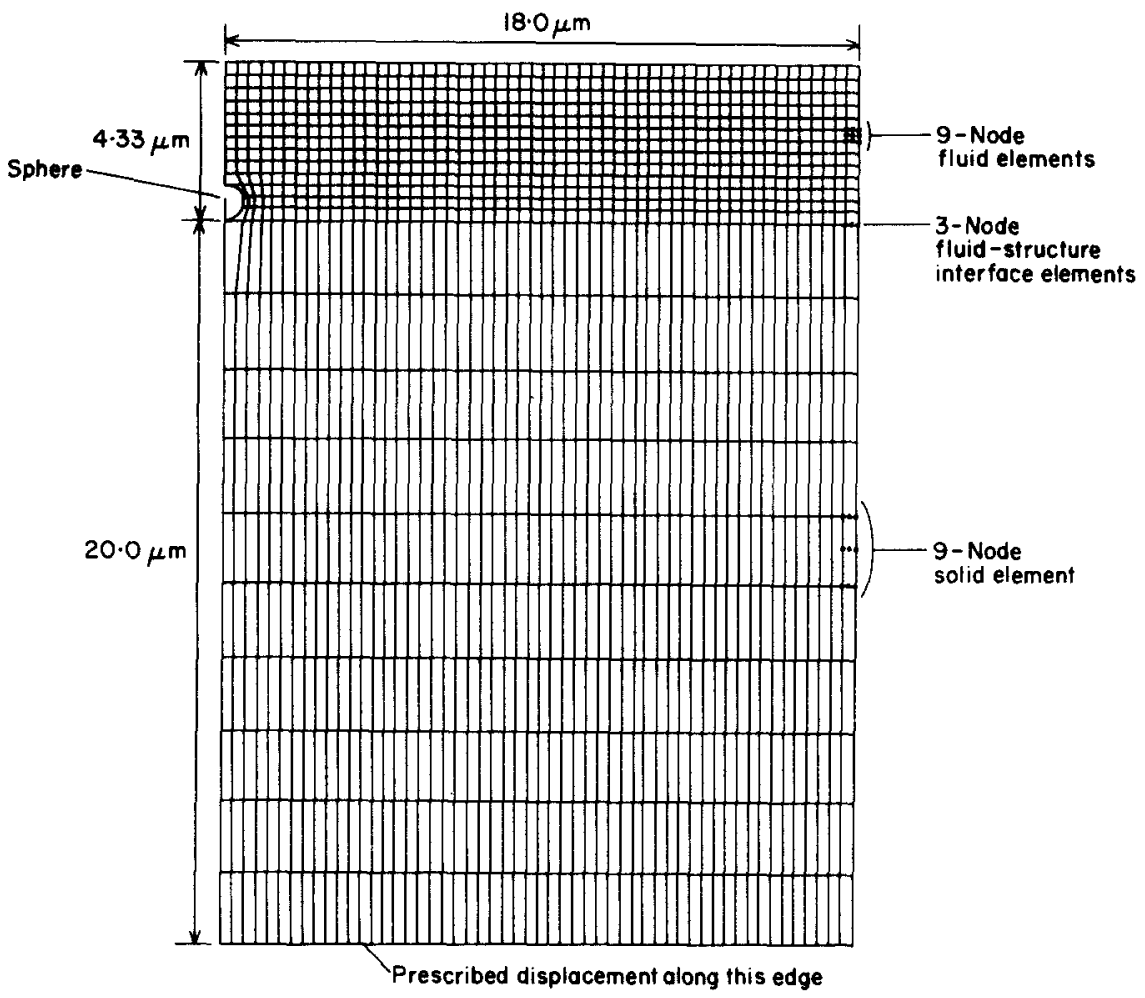

Figure 22. Finite element mesh for $1 \mathrm{GHz}$ case.

\section{DISCUSSION}

The force on a sphere resting on a fluid-structure interface has been found for three frequencies by using the $\phi-U-P_{0}$ method. Table 1 summarizes these forces which are due to an incident wave with $1 \mu \mathrm{m}$ amplitude. The greatest force on the sphere occurred at the highest frequency $(1 \mathrm{GHz})$. At this frequency, the acoustic wavelength is roughly equal to the diameter of the sphere. The linear analysis can be scaled to compare waves of equal input energies $(e): e=$ stress $\times$ velocity $=E(\partial U / \partial x)(\partial U / \partial t)$. The input wave is sinusoidal with amplitude $B$,

$$
U=B \sin \left(\frac{z}{c_{s}}-t\right)
$$






Figure 23. Finite element mesh near sphere for $1 \mathrm{GHz}$ case.



Figure 24. Force on sphere for $1 \mathrm{GHz}$ case.

TABLE 1

Force on sphere due to a $1 \mu \mathrm{m}$ amplitude wave

\begin{tabular}{cc}
\hline Frequency (MHz) & Force (dynes) \\
\hline 10 & $0 \cdot 015$ \\
100 & $1 \cdot 5$ \\
1000 & 130 \\
\hline
\end{tabular}


which means that the relationship between the input energy and the amplitude becomes

$$
e \approx E \omega^{2} B^{2} / c_{s}, \quad B \approx \sqrt{c_{s} e / E(1 / \omega)} .
$$

Table 2 gives the force on the sphere for incident waves with $1 \mathrm{~W} / \mathrm{cm}^{2}$ and $10 \mathrm{~W} / \mathrm{cm}^{2}$ energies. The higher frequency waves produce larger particle forces even for the same energy input. Therefore, this baseline linear finite element analysis suggests that very high frequencies $(\approx 1 \mathrm{GHz}$ ) will be required to remove submicron contaminants from wafers.

Other factors could become important at these high frequencies, indicating that more detailed non-linear finite element analyses might prove useful. Non-linear wave propagation effects and weak shock development (resulting in a "sawtooth" wave) are likely to be important. Different particle geometries or sawtooth wave incidence angles may result in very different particle forces. Nevertheless, the author feels that this linear analysis provides a valuable starting point for future research.

TABLE 2

Adjusted force on sphere

\begin{tabular}{cccc}
\hline $\begin{array}{c}\text { Frequency } \\
(\mathrm{MHz})\end{array}$ & $\begin{array}{c}\text { Energy, } e \\
\left(\mathrm{~W} / \mathrm{cm}^{2}\right)\end{array}$ & $\begin{array}{c}\text { Amplitude, } B \\
(\mu \mathrm{m})\end{array}$ & $\begin{array}{c}\text { Force } \\
(\text { dynes })\end{array}$ \\
\hline 10 & 1.0 & $3.5 \times 10^{-4}$ & $5.2 \times 10^{-6}$ \\
& 10.0 & $1.1 \times 10^{-3}$ & $1.7 \times 10^{-5}$ \\
100 & 1.0 & $3.5 \times 10^{-5}$ & $5.2 \times 10^{-5}$ \\
& 10.0 & $1.1 \times 10^{-4}$ & $1.7 \times 10^{-4}$ \\
1000 & 1.0 & $3.5 \times 10^{-6}$ & $4.5 \times 10^{-4}$ \\
& 10.0 & $1.1 \times 10^{-5}$ & $1.4 \times 10^{-3}$ \\
\hline
\end{tabular}

\section{ACKNOWLEDGMENTS}

The author wishes to thank International Business Machines Corporation for their support of this study.

\section{REFERENCES}

1. L. G. Olson and K. J. BATHE 1985 Computers and Structures 21, 21-32. Analysis of fluidstructure interactions. A direct symmetric coupled formulation based on the fluid velocity potential.

2. L. G. Olson and K. J. BATHE 1985 Engineering Computations 2, 319-330. An infinite element for analysis of transient fluid-structure interactions.

3. G. C. EVERSTINE 1981 Journal of Sound and Vibration 79, 157-160. A symmetric potential formulation for fluid-structure interaction (letter to the editor).

4. G. C. EVERSTINE 1982 Proceedings of the 6th Invitational Symposium on the Unification of Finite Elements, Finite Differences, and Calculus of Variations, ed. H. Kardestuncer, University of Connecticut, 101-122. Structural-acoustic finite element analysis, with application to scattering.

5. G. C. Everstine, M. S. MARcus and A. J. Quezon 1983 Eleventh NASTRAN User's Colloquium, NASA Conference Publication, 141-160. Finite element analysis of fluid-filled elastic piping systems.

6. T. B. BELYTSCHKO and J. M. KENNEDY 1978 Nuclear Engineering and Design 49, 17-38. Computer models for subassembly simulation.

7. T. BelYtschko and U. SchumanN 1980 Nuclear Engineering and Design 60, 173-195. Fluid-structure interactions in light water reactor systems.

8. T. BELYTSCHKO and R. MULLEN 1981 Computer Methods in Applied Mechanics and Engineering 27, 139-154. Two dimensional fluid-structure impact computations with regularization. 
9. T. B. BELYTSChKo and D. P. FlanAGiN 1981 International Journal for Numerical Methods in Engineering 17, 676-706. A uniform strain hexahedron and quadrilateral with orthogonal hourglass control.

10. K. J. BAIHE and W. HAHN 1978 Computers und Structures 10, 383-391. On transient analysis of fluid-structure systems.

11. L. G. OlSON and K. J. BATHE 1983 Nuclear Engineering and Design 76, 137-151. A study of displacement-based fluid finite elements for calculating frequencies of fluid and fluid-structure systems.

12. G. LARSSON and P. SVENKVIST 1979 Proceedings of the ADINA Conference, 383-406. Experiences using the ADINA fluid element for large displacement analysis.

13. J. SUNDQVIST 1983 Computers and Structures 17, 793-807. An application of ADINA to the solution of fluid-structure interaction problems.

14. E. L. WIISON 1977 in Finite Elements in Geomechanics (editor Gudehus). New York: John Wiley. (This paper was presented at the International Symposium of Numerical Methods in Soil Mechanics and Rock Mechanics, Karlsruhe, September 1975.)

15. E. L. WILSON and M. KHALVATI 1983 International Journal for Numerical Methods in Engineering 19, 1657-1668. Finite elements for the dynamic analysis of fluid-solid systems.

16. T. A. SHUGAR and M. G. KATONA 1975 Journal of the Engineering Mechanics Division, ASCE (June), 223-239. Development of a finite element head injury model.

17. T. B. KHALIL and R. P. HuBBARD 1977 Journal of Biomechanics 10, 119-132. Parametric study of head response by finite element modelling.

18. M. A. HAMDI, Y. OUSSET and G. VERCHERY 1978 International Journal for Numerical Methods in Engineering 13,139-150. A displacement method for the analysis of vibrations of coupled fluid-structure systems.

19. L. KIEFLING and G. C. FENG 1976 American Institute of Aeronautics and Astronautics Journal 14, 199-203. Fluid structure finite element vibrational analysis.

20. N. AkKas, H. U. AKAY and C. Yilmaz 1979 Computers and Structures 10, 773-783. Applicability of general-purpose finite element programs in solid-fluid interaction problems.

21. O. C. ZIENKIEWICZ and R. E. NEWTON 1969 Symposium on Finite Element Techniques, Stuttgart. Coupled vibrations of a structure submerged in a compressible fluid.

22. W. J. T. DANIEL 1980 International Journal for Numerical Methods in Engineering 15, 1161-1175. Modal methods in finite element fluid-structure eigenvalue problems.

23. M. PETYT and S. P. LIM 1978 International Journal for Numerical Methods in Engineering 13, 109-122. Finite element analysis of the noise inside a mechanically excited cylinder.

24. W. C. MULlER 1981 International Journal for Numerical Methods in Engineering 17, $113-121$. Simplified analysis of linear fluid-structure interaction.

25. A. CRAGGS 1971 Journal of Sound and Vibration 15, 509-528. The transient response of a coupled plate-acoustic system using plate and acoustic elements.

26. O. C. ZIENKIEWICZ and P. BETTESS 1978 International Journal for Numerical Methods in Engineering 13, 1-16. Fluid-structure dynamic interaction and wave forces-an introduction to numerical treatment.

27. T. BELYTSCHKO 1980 Computers and Structures 12, 459-469. Fluid-structure interaction.

28. P. M. MORSE 1976 Sound and Vibration. Acoustical Society of America.

29. F. B. HildeBRAND 1976 Advanced Calculus for Applications (2nd Edition), Englewood Cliffs, N.J.: Prentice-Hall.

30. K. J. BAthe Finite Element Procedures in Engineering Analysis. Englewood Cliffs, N.J.: PrenticeHall.

31. T. J. R. HUGHES and T. BELYTSCHKo 1983 Journal of Applied Mechanics 50, 1033-1041. A precis of developments in computational methods for transient analysis.

32. O. C. ZIENKIEWICZ, D. W. KELLEY and P. BetTESS 1979 Lecture Notes in Mathematics 704. The Sommerfeld (radiation) condition of infinite domains and its modelling in numerical procedures.

33. C. C. MEI 1978 Annual Review of Fluid Mechanics 10, 393-416. Numerical methods in water-wave diffraction and radiation.

34. P. BETTESS and O. C. ZIENKIEWICZ 1979 International Journal for Numerical Methods in Engineering 11, 1271-1290. Diffraction and refraction of surface waves using finite and infinite elements.

35. T. L. GEERS 1978 Journal of the Acoustical Society of America 64, 1500-1508. Doubly asymptotic approximations for transient motions of submerged structures. 